\title{
Fossil rootlet biopores as conduits for contaminant transport through clay horizons: a case study of DNAPL behaviour in Severn alluvium, UK
}

\author{
D. Emanuel $^{1}$ • D. J. Sapsford ${ }^{2}$
}

Received: 6 March 2015 / Accepted: 18 May 2016/Published online: 4 June 2016

(c) The Author(s) 2016. This article is published with open access at Springerlink.com

\begin{abstract}
This paper presents a case study of several DNAPL contaminated sites around the Severn Estuary (UK) where a combination of detailed observations, core dissections and physicochemical characterisation of alluvial clay-silt horizons have revealed the presence of fossil rootlet biopores which act and have the potential to act as conduits for contaminant migration through up to $13 \mathrm{~m}$ of clay-silt. The biopores are shown to penetrate the lowpermeability $\left(K \sim 10^{-10} \mathrm{~m} / \mathrm{s}\right.$ ) clay-silt matrix throughout its entire depth (up to $13 \mathrm{~m}$ ) and provide a preferential transport pathway for DNAPLs from near surface to the underlying aquifer, with particularly high concentrations measured in the biopores themselves. Capillary rise experiments with coal tar distillate demonstrate that DNAPLs are drawn into biopores, with values of surface interfacial tension for the system calculated as $8 \times 10^{-2} \mathrm{~J} /$ $\mathrm{m}^{2}$. Wicking by residual plant fibres was demonstrated qualitatively and is thought to be an important additional transport mechanism. The DNAPL contamination below and throughout the Severn alluvial clay-silt horizons demonstrates that the assumption that these horizons act as an effective seal protecting underlying aquifers from severe pollution from the legacy sites around the Severn is flawed and highlights the failure of current protocols for sampling of clay horizons for hydraulic conductivity assessments, since current methods can destroy delicate in situ biopore
\end{abstract}

\footnotetext{
D. J. Sapsford

sapsforddj@cf.ac.uk

D. Emanuel

dave@terrafirmawales.co.uk

Terra Firma Wales Ltd, Cardiff, UK

2 Cardiff School of Engineering, Cardiff University, Cardiff, UK
}

structures. The study demonstrates that the interplay between ecological and the geological depositional environment can, at a regional scale, result in a network of biopores that can potentially act as conduits for contaminant transport.

Keywords Environmental risk assessment $\cdot$ Coal tar · Coal tar distillates · Pollution

\section{Introduction}

Whilst clay horizons and other low-permeability soil and sediment horizons have low matrix hydraulic conductivities of $10^{-9}-10^{-10} \mathrm{~m} / \mathrm{s}$, the literature has documented several phenomena such as fractures, macropores and biopores that can dramatically increase hydraulic conductivity (e.g. Douglas 1986; Driese et al. 2001; McKay et al. 1999, 2005; McKay and Fredericia 1995; Rodvang and Simpkins 2001; Rudolf et al. 1991; Shaw and Hendry 1998) and the permeability with respect to contaminants such as coal tar and coal tar distillate polycyclic aromatic hydrocarbons (e.g. Hinsby et al. 1996; Vulava et al. 2007). Biopores are specifically holes that occur in soils/sediments due to plant growth and/or the action of animals earth worms (Oades 1993; Edwards et al. 1988). Edwards et al. (1988) demonstrate the significant contribution of such biopores to groundwater flow and also acknowledge the technical difficulties in recording the distribution and effect of such features.

White et al. (2008) highlight that most studies refer to permeability-enhancing features at ground surface and to the author's knowledge, White et al. (2008) study is the only other published one (prior to this one) that shows the importance of a paleohorizon and the biopores it contains 
for contaminant transport. In the White et al. (2008) study, non-aqueous phase liquids (NAPLs) penetrated through $0.5-2.0 \mathrm{~m}$ of clay, and this study extends the envelope of this phenomenon to $\sim 13 \mathrm{~m}$ of clay-silt. Movement of dense NAPLS (DNAPLs) through biopores depends on critical parameters such as pore width and entry pressure, pore interconnectedness (Jørgensen et al. 1998) and surface wetting phenomena controlled by the intermolecular interaction between a contaminant and a soil mineral surface.

This case study concerns coal tar and coal tar derivatives comprised of viscous multicomponent hydrocarbon DNAPLs with a low aqueous solubility. A large number of former industrial sites in the UK have been investigated for DNAPL contamination, and this type of site is common in other countries, for example, there are 50,000 estimated former manufactured gas plants in the USA (Mueller et al. 1989). Given the human and environmental toxicity of coal tar, extensive risk assessment is necessary when redeveloping such sites. In environmental risk assessments, alluvial clay is often assumed to be an effectively impermeable stratum and has thus been assumed to provide an effective barrier against the migration of DNAPLs. However, our field observations are contrary to this hypothesis with free phase and dissolved phase coal tar, and coal tar derivatives having been seen to penetrate over $13 \mathrm{~m}$ thickness of alluvium through biopores to reach the gravel aquifer beneath.

The aims of this paper are (1) to present a case study that documents the occurrence of fossil rootlet biopores and demonstrates that this is a regional occurrence (2) to physically characterise and chemically characterise DNAPL contaminated pores (3) to demonstrate that fossil rootlets are responsible for the transport of DNAPL contamination through clay horizons (4) to demonstrate that conventional sampling protocols do not record these important structures (5) to investigate capillary rise in empty and fossil plant fibre-filled biopores and plant fragments.

\section{Severn Estuary study sites}

The study sites described in this study are all located close to cities with historically industrialised dock areas around the Severn Estuary, UK (Fig. 1). DNAPL contamination is commonly found in low-lying coastal and estuarine sites in the UK because of historic associations with the use of coal for town gas production and associated by-product industries. In addition to the proximity of historic industrial users of town gas, the estuary-side low-lying locale was desirable both from a distribution cost perspective: to allow the gas mixture which was lighter than air to rise throughout the network to the consumer and to locate sites near a transport network (Hatheway 2002). The study sites considered in this research have been formerly occupied by or lay adjacent to industrial facilities which generated coal tar as a by-product (i.e. manufactured gas plant) or stored and used refined products of coal tar (i.e. tar distillery and wood treatment plants). Furthermore, the common historic practice of placing tar in unlined pits has resulted in these facilities being heavily contaminated at shallow depth

Four study sites around the Severn Estuary are considered in the current research, all with a history of coal tar manufacture and/or coal tar distillation. The sites are summarised in Table 1.

\section{Severn Estuary geology}

A mantle of made ground was encountered at all four study sites although this is not detailed in the following discussion as the made ground material was highly variable and does not lend itself to generalised description. Alluvium lies beneath the made ground. The superficial alluvium deposits encountered at the four study sites were seen to have a number of characteristics in common. The published 1:50,000 scale Geological Maps [British Geological Survey (BGS) Sheets 263 (1986b, Cardiff), 249 (1975, Newport) and 279 (1980, Weston-super-Mare)] date the deposits as Pleistocene (see Jones and Keen 1993) to recent. The areal extent of these deposits around the Severn Estuary is displayed in Fig. 2.

The Geological Memoir for the Newport Geological Sheet (Squirrell and Downing 1969) indicates that the coastal flats of the Bristol Channel are covered by alluvium comprising mud and silt, deposited during post-glacial sea transgressions. Particle size distribution (PSD) testing performed as part of this research was undertaken on samples of alluvium (data not shown), and this confirmed that the alluvium at the four sites was dominated by clay and silt. Subordinate and discontinuous peat horizons are present within the clay and silt deposits, and these peat bands represent halts in the transgression with episodes of marine regression followed by an episode of fen, Carr and raised bog development, perhaps with minor marine fluctuations, which was in turn succeeded by a further phase of estuarine sedimentation (Allen and Fulford 1986). The Geological Memoir for the Bristol Geological Sheet (Kellaway and Welch 1993) suggests that eastwards of a notional line between Newport and Weston-super-Mare (see Fig. 2), estuarine alluvium was deposited during the Flandrian (10,000 Before Present (BP) to present), commencing at a time of low sea level c. 9000 years BP followed by a marine transgression. The basal deposits of the alluvium comprise sandy gravel deposits indicative of a higher energy depositional environment. At Weston-superMare, the basal gravel was very clayey. The geology at the 


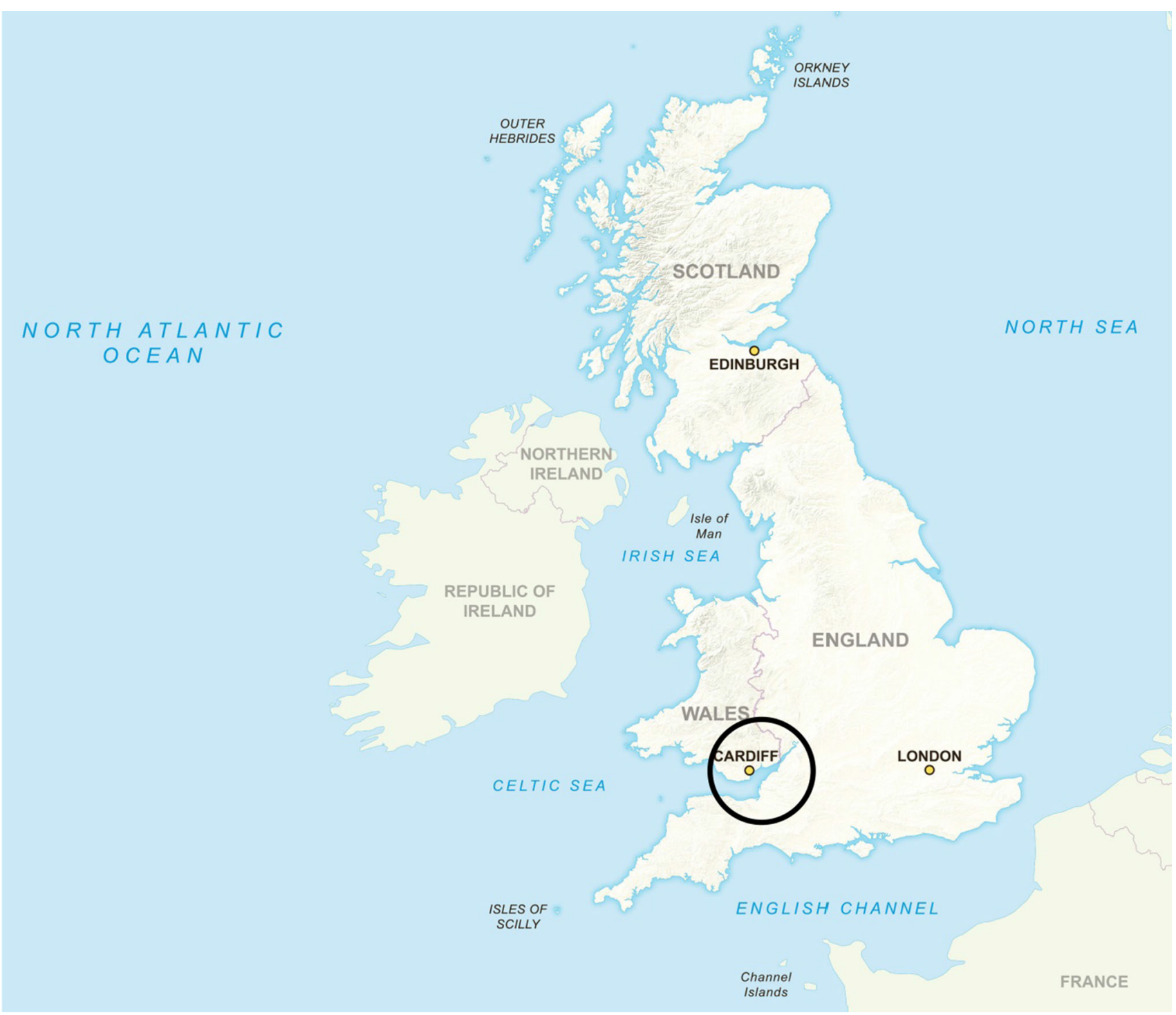

Fig. 1 UK Map with circle indicating the location of the Severn Estuary (compare to Fig. 2 below with Cardiff as reference). Contains Ordnance Survey data (C) Crown copyright and database right 2014, (http://www.ordnancesurvey.co.uk/docs/licences/os-opendata-licence.pdf)

study sites is summarised in Table 1, although minor local variations in thickness were encountered within the study sites. The superficial deposits are underlain at all sites by the Triassic Mercia Mudstone (BGS Sheet 249, 1975; BGS Sheet 263, 1986b; BGS Sheet 279, 1980; BGS Sheet 264, British Geological Survey 1986a). The depth at which the confined aquifer was recorded at the study sites is also summarised in Table 1.

\section{Field and laboratory methods}

Of the four study sites considered in this case study, much of the detailed characterisation work comes from samples from the Sites A and B

\section{Boreholes and core logging}

Investigations were performed using light cable percussion boreholes, investigation strategies were performed in accordance with BS:EN 10175 (2001), and soils were logged in accordance with BS:5930 (1999). Soil samples and groundwater samples were collected during site investigations around the Severn Estuary and submitted for chemical analysis at commercial laboratories (see below). During site investigations at Site A, an almost continuous run of $100 \mathrm{~mm}$ diameter, $450 \mathrm{~mm}$ length, undisturbed samples (U100s) were collected from alluvial deposits in three boreholes. Detailed logging was carried out on selected soil samples of alluvium. A range of sample types were appraised predominantly comprising U100s, $35 \mathrm{~mm}$ 
Table 1 Summary of the history of the study sites located on the Severn Estuary Alluvium and generalised ground conditions beneath

\begin{tabular}{|c|c|c|c|c|c|c|}
\hline \multirow[t]{2}{*}{$\begin{array}{l}\text { Site } \\
\text { reference }\end{array}$} & \multirow[t]{2}{*}{ Site history } & \multirow{2}{*}{$\begin{array}{l}\text { Approximate ground } \\
\text { level elevation ( } \mathrm{m} \text {. } \\
\text { A.O.D.) }\end{array}$} & \multirow{2}{*}{$\begin{array}{l}\text { Depth to } \\
\text { confined } \\
\text { aquifer }(\mathrm{m})\end{array}$} & \multicolumn{3}{|c|}{$\begin{array}{l}\text { Depth to base of deposit ( } \mathrm{m} \text { below ground } \\
\text { level) }\end{array}$} \\
\hline & & & & $\begin{array}{l}\text { Alluvial silt and } \\
\text { clay with } \\
\text { subordinate peat }\end{array}$ & $\begin{array}{l}\text { Alluvial } \\
\text { sandy } \\
\text { gravel }\end{array}$ & $\begin{array}{l}\text { Bedrock } \\
\text { geology }\end{array}$ \\
\hline A & $\begin{array}{l}\text { Timber yard est. } 1884 \text { with a history of } \\
\text { creosote usage }\end{array}$ & $10.3 \mathrm{~m}$ & 13.2 & 13.2 & 19.2 & \multirow{4}{*}{$\begin{array}{l}\text { Mercia } \\
\text { Mudstone } \\
\text { Group }\end{array}$} \\
\hline B & $\begin{array}{l}\text { Rosin and tar Distillery since c. } 1901 \text { to } \\
\text { c. } 1940 \text { and contained tanks until c. } 1975\end{array}$ & $10.0 \mathrm{~m}$ & 9.2 & 9.2 & 10.5 & \\
\hline $\mathrm{C}$ & $\begin{array}{l}\text { Gasworks located immediately south-west of } \\
\text { the site pre-1887. Adjacent site still holds } \\
\text { gas apparatus }\end{array}$ & $5.0 \mathrm{~m}$ & - & 26.4 & 28.5 & \\
\hline D & $\begin{array}{l}\text { Gas works occupied site from pre-1870. } \\
\text { Gasworks closed between } 1931 \text { and } 1966\end{array}$ & $8.5 \mathrm{~m}$ & 14.9 & 14.9 & 15.0 & \\
\hline
\end{tabular}

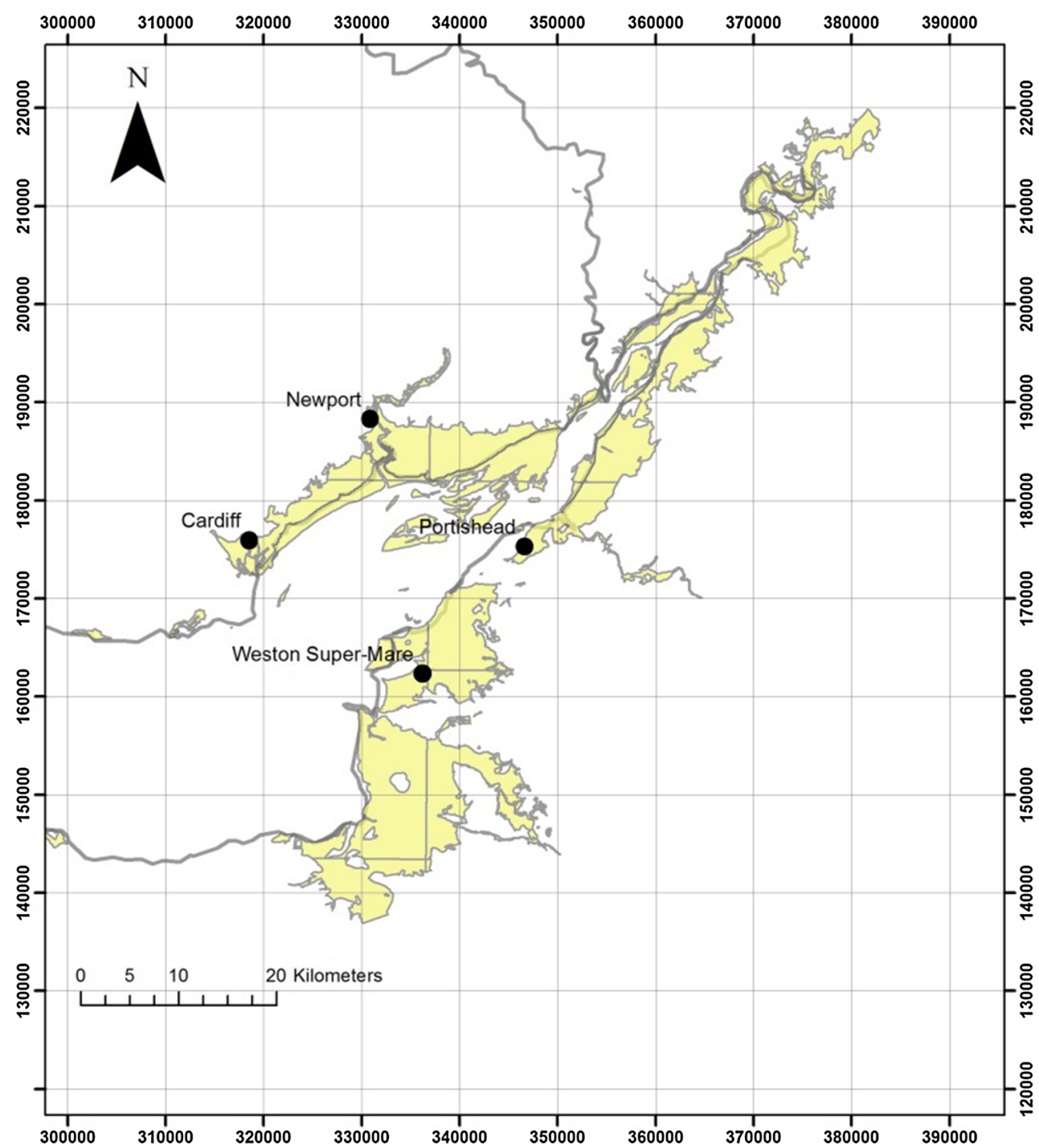

Fig. 2 Extent of Severn Estuary Alluvium (supplied with permission from British Geological Survey) 
split-spoon samples, clay cutter samples and lined windowless sampler borehole cores. Samples were obtained from contaminated and uncontaminated sites.

\section{Physical measurements}

The deformation characteristics of clay soil, and thus its ability to preserve fine structures during sampling and handling, are related to the soils moisture content and corresponding plastic and liquid limits. Selected soil samples from Site A were subject to moisture content analysis, and the liquid limit and plastic limit of the alluvium were determined for a representative sample of alluvium from $9.00 \mathrm{~m}$ depth in accordance with BS1377 (Part 2: 1990). During drilling at the study sites in situ, standard penetration tests (SPTs) were performed at regular intervals. SPTs were performed in accordance with the methods described Section 9 of BS1377 (1990) using a split-spoon sampler. Continuous core samples of alluvium from a borehole at Site A were tested for hydraulic conductivity BS:1377:1990 by a commercial laboratory.

\section{Chemical analysis of soil matrix and biopores}

Fifteen-eighteen samples were taken with depth for each of three boreholes at Site A, and samples were homogenised, sub-sampled and submitted to a commercial laboratory for EPA 16 PAH analysis. The distribution of tar compounds in and within the vicinity of biopores was determined as follows: selected contaminated soil samples from Site A and D were carefully dissected using dental scalars to isolate the material contained within the pores and the soil immediately surrounding the pores from the remaining soil matrices. Following separation, the samples were dried in an oven at $40{ }^{\circ} \mathrm{C}$ for $48 \mathrm{~h}$, crushed and weighed into samples of approximately $1 \mathrm{~g}$ mass. The dried samples underwent solvent extraction using an accelerated solvent extraction system (Dionex ASE100). Dichloromethane was used as a solvent with excess anhydrous sodium sulphate as a desiccant. The solvent extract was subject to speciated PAH analysis by gas chromatography-mass spectrometry (GC-MS) performed on a Perkin-Elmer Clarus 500. PAH identities were confirmed and quantified against a $50 \mathrm{ppm}$ PAH standard (Restek). In addition, the molecular fragments weights and eluting times were compared to a database from the National Institute of Standards and Technology (NIST) for further confirmation of the identity of individual species.

The mineralogy of selected alluvium samples from various depths was determined by XRD analyses. The samples comprised alluvial clay-silt. The samples were collected from uncontaminated soils. The selected samples were prepared by desiccation in an oven at $40{ }^{\circ} \mathrm{C}$ for $48 \mathrm{~h}$ and subsequently ground to a fine powder and then analysed by XRD (Phillips PW3830 X-ray Diffraction Analyser).

\section{Biopore size measurements}

Detailed measurements of pore diameters were made during borehole logging using digital callipers. The crosssectional area of the logged core varied depending on the drilling technique used (U100 s, clay cutters, standard split-spoon samplers and windowless samplers). The logged samples were sometimes fragments of the whole cores, in which case the samples were measured to deduce their cross-sectional area. Biopore data from twenty-two samples were taken from a range of depths at Site A and Site C. The cross-sectional area of the pores was calculated from their recorded diameter, assuming the pores were circular. Since the cross-sectional area and number of the pores of each size range were known, along with the cross-sectional area of the sample, the number of pores per $\mathrm{m}^{2}$ of soil could be estimated.

\section{Capillary rise experiments}

A portion of the pores encountered in the alluvium contained fossil plant fragments. Capillary rise experiments were performed using fossil plant fragments to provide qualitative evidence that the fossil plant fragments could serve as a means of DNAPL transport via capillary flow. The fragments were predominantly fibrous and roughly circular in cross section with diameters typically $<2.5 \mathrm{~mm}$, being predominantly orientated in a vertical to sub-vertical position. Larger irregular fragments were encountered in peat bands and as isolated fragments in random orientation. All fossil plant fragments were extremely delicate once removed from the surrounding soil matrix. Initially, fossil plant fragments were carefully isolated from $4.0 \mathrm{~m}$ (Sample 1) and $13 \mathrm{~m}$ (Sample 2) depth, Site A, by careful dissection. Due to the delicate nature of the plant fibres, samples of length greater than $32 \mathrm{~mm}$ could not be isolated. Soil samples were collected from a non-contaminated area of the site and did not initially contain any coal tar distillate. Sample 1 was obtained from above the groundwater where soil moisture content was determined to be $33 \%$. Sample 2 was obtained from below the groundwater where soil moisture content was determined to be $57 \%$.

Five samples of plant fibres from both soil samples were successfully isolated. Each fibre was individually suspended vertically above a dish of representative coal tar distillate with one end of the sample contacting the distillate. To assess the flow behaviour of coal tar distillate in biopores containing plant fibres in the confinement of the 
soil matrix, an undisturbed and uncontaminated soil sample (U100) from 9.00 to $9.45 \mathrm{~m}$, Site B, was placed in a pool of distillate such that the base of the sample sat in $5 \mathrm{~mm}$ depth of liquid.

Capillary rise within open pores (i.e. without plant material) was studied using clay samples taken from $8.0 \mathrm{~m}$ depth from Site A and $9.0 \mathrm{~m}$ depth from Site B. The clay samples had a measured moisture content of 47 and $42 \%$, respectively. Moisture content testing after the conclusion of the experiments did not reveal significant changes in moisture content during the experiment. The clay was kneaded to homogenise the material and rolled into cylinders approximately $150 \mathrm{~mm}$ in length. Small diameter holes were drilled through the centre of the clay cylinders using drill-bits or, below $1.0 \mathrm{~mm}$, thin brass rods of known diameter. The diameters were confirmed with vernier callipers. The bases of the cylinders were then submerged in a shallow bath of representative coal tar distillate. Prior to performing the main experiments, samples were left in the bath for periods from $60 \mathrm{~s}$ to $2 \mathrm{~h}$ which revealed that equilibrium was achieved within the pores in less than $60 \mathrm{~s}$. All experiments were performed at $20^{\circ} \mathrm{C}$. Test samples were left in the bath for a period of $1 \mathrm{~h}$ after which the cylinders were removed from the bath and split. The capillary rise of the coal tar distillate was calculated by measuring the length of the stain within the capillary compared to the submerged depth of the sample. Tests at each diameter were performed in triplicate. Capillary rise was also examined using narrow diameter glass tubing as an analogy to the silicate minerals observed in the Severn Estuary alluvium. Glass capillary tubing with internal diameters of $0.90,1.10$ and $2.80 \mathrm{~mm}$ were suspended vertically within coal tar distillate. The tubing was left with their bases in coal tar distillate for $24 \mathrm{~h}$ before measurement. The rise within the tubing was recorded using digital callipers.

\section{Results and discussion}

\section{General field observations}

Fossil rootlet biopores were observed throughout clay-silt alluvium horizons from all four of the study sites located on both sides of the Severn Estuary (Fig. 3). The following generalised field observations on contaminant distribution were made during on-site coring and logging, providing qualitative evidence as to the transport behaviour of coal tar distillate and coal tar compounds in the alluvium:

1. Beneath the locations of former plant areas, there was significant visual and olfactory evidence of coal tar/coal tar distillate contamination within the made ground, including pockets of free product within interstitial space.

2. Beneath the location of former industrial plant areas, there was visual and olfactory evidence of coal tar/coal tar distillate contamination within the alluvial clay. Discolouration (black staining) was seen to occur within vertical to sub-vertical fossil root structures and remnant root material.

3. Deep groundwater from beneath the alluvium was observed to contain droplets of hydrocarbon free product beneath plant areas and down hydraulic gradient. The hydrocarbon was seen to sink within sample jars under quiescent conditions. This clearly demonstrated that DNAPL contamination has traversed the alluvium and impacted the aquifer beneath (cf. Jørgensen et al. 1998).

4. Alluvial clays were almost always 'soft' to 'very soft' indicating high moisture contents, approaching or exceeding the soils liquid limit. The clay structure was extremely susceptible to disruption during sampling, handling and sample preparation.

\section{Detailed observations and physical properties of cored materials}

The detailed logging of samples from the four study sites has revealed that the alluvial clay-silt exhibits consistent physical characteristics throughout the Severn Estuary. Consistent with the geological memoirs of the area, the alluvium was seen to comprise predominantly clay-silt size minerals with subordinate bands of peat and usually a basal gravel. Alluvial peat and clay was often 'firm' near the surface due to desiccation, soon becoming soft to very soft with depth. During the detailed logging, it was apparent that the Severn Estuary alluvium contained a number of structural features: the clay-silt was often thinly laminated, and the matrix of the clay-silt was often penetrated by biopores (see Fig. 3). The biopores were almost always vertical to sub-vertical in orientation. Pores either contained fibrous plant fragments (e.g. Fig. 3d), which partially or completely filled the pore, or were completely open. This indicates that the biopores are fossil rootlets/rootlet structures rather than due to bioturbation. Some pores were observed to terminate within samples, whilst others were seen to extend throughout the length of the longest samples (up to $450 \mathrm{~mm}$ length in the case of U100 samples). In material collected from contaminated areas, the biopores were often coal tar/coal distillate stained and malodorous when filled with DNAPL. Contaminated pores were observed beneath the phreatic level, suggesting water can be displaced from the pores by the DNAPLs. Pore structures were less prevalent beneath the phreatic horizon. 


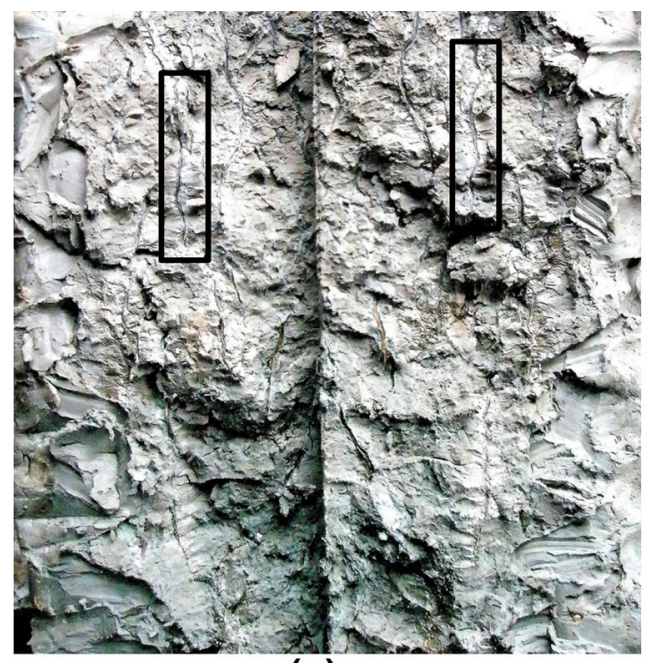

(a)

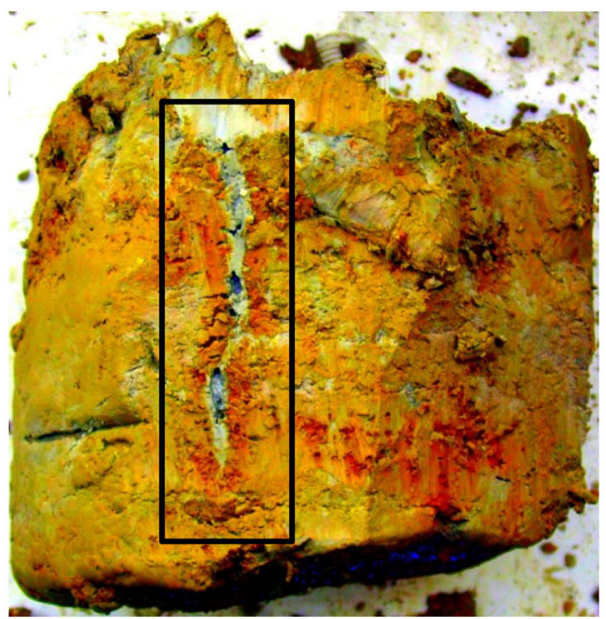

(c)

Fig. 3 Photographs of core samples from site investigations. Note that images have been manipulated with Google Picasa 3 to ease identification of pore structures. a Split of undisturbed core $(100 \mathrm{~mm}$ diameter) sample from borehole depth 9.00-9.45 m, Site B, numerous vertical/sub-vertical fossil rootlets visible b horizontal section of a $35 \mathrm{~mm}$ SPT -spoon sample, borehole depth $4.00-4.45 \mathrm{~m}$, Site D

The presence of residual organic material below the current phreatic horizon indicates conditions were conducive to plant growth during deposition. The phreatic horizon would have risen with sea-level rise, and this is consistent with the recent geological history of the area, marked latterly by a marine transgression. The pore structures were observed in samples from the study sites located on both sides of the Severn Estuary.

\section{Physical characteristics of clay horizons}

The strength [in accordance with the uni-axial compressive strength categories, BS:5930(1999)] of Severn Estuary alluvial silt-clay and peat is generally 'soft' to 'very soft',

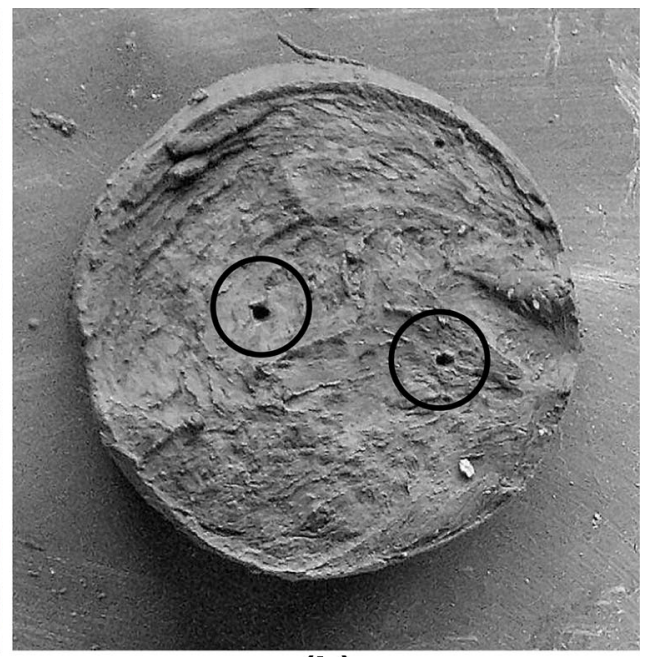

(b)

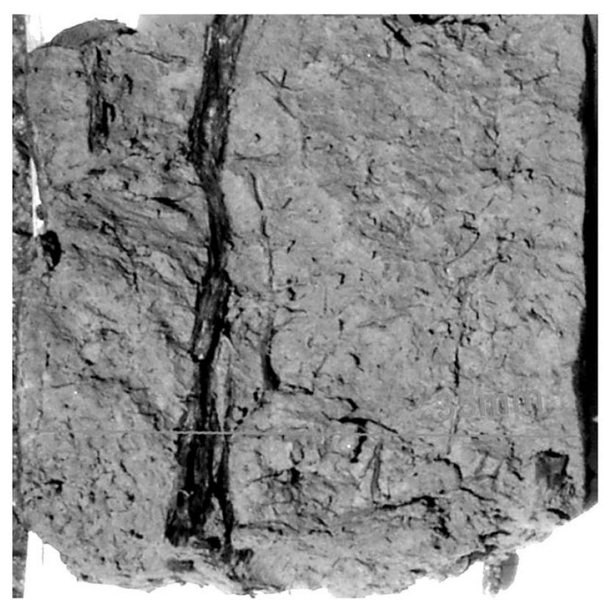

(d)

c vertical section of alluvium from core (100 $\mathrm{mm}$ diameter), borehole depth $6.00-6.45 \mathrm{~m}$, Site A, grey infilled vertical pore structure is clearly seen as clay infill into the silt. d Vertical section of alluvium from $35 \mathrm{~mm}$ SPT spoon sample, borehole depth 3.00-3.45 m, Site C $2.3 \mathrm{~mm}$ diameter pore with plant fibres clearly visible, hydrocarbon odours noted

although desiccated crusts were sometimes encountered at shallow depth which exhibit 'firm' consistency. The majority of the alluvial sediment has a moisture content approaching or exceeding the soils plastic limit, and claysilt sediments were typically soft to very soft. Figure 4 shows the smearing and destruction of pores by cutting core compared with breaking the core, and it is apparent that cutting removes traces of the biopores. The low strength and plasticity of the clay samples make the observed biopores very susceptible to disruption during sampling and subsequent handling. The soils become modified during preparation for hydraulic conductivity testing by standard methods, resulting in incorrect measurement of the true in situ hydraulic conductivity. 
Recorded hydraulic conductivity results ranged from values of $4 \times 10^{-11} \mathrm{~ms}^{-1}$ for slightly gravelly silty-clay through to $6.2 \times 10^{-10} \mathrm{~ms}^{-1}$ for silty-clay with a mean and stdv of $2.9 \times 10^{-10} \pm 2.1 \times 10^{-10} \mathrm{~ms}^{-1}$ based on 14 samples at depths between 5.5 and $14.7 \mathrm{~m}$ at Site A. It is noteworthy that the typical procedure for preparing a groundwater risk assessment would be based on such data. Testing of material from the confined sand and gravel aquifer beneath the clay horizons had a measured permeability of $6.8 \times 10^{-4} \mathrm{~ms}^{-1}$.

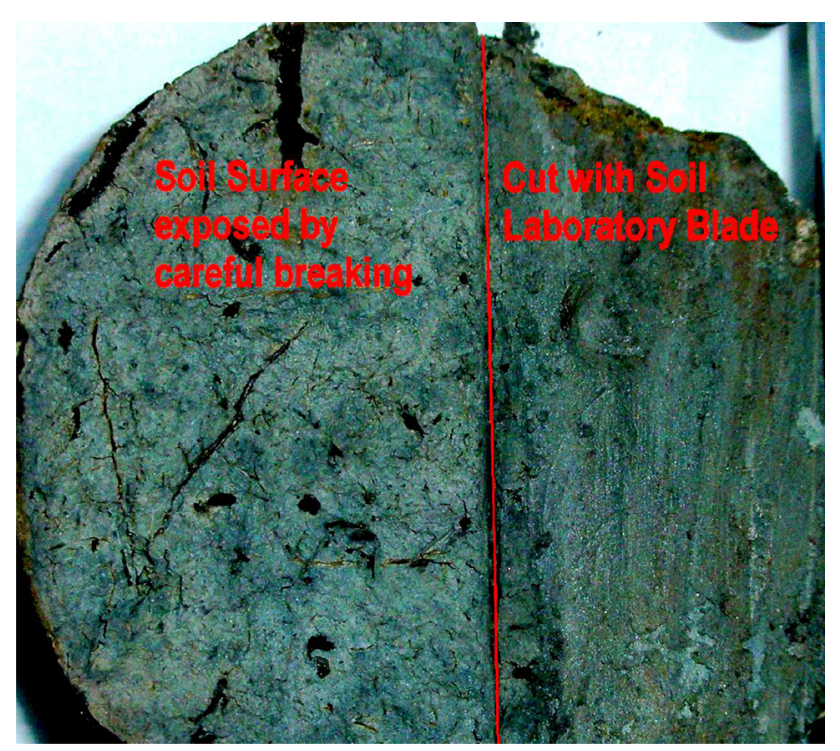

Fig. 4 Example of damage caused to biopores by sample trimming

\section{Mineralogy and contaminant analyses of homogenised core samples}

XRD analyses showed that mineralogically, the alluvium across the Severn Estuary is dominated by silicate mineralogy (illite, montmarillonite and kaolinite) and that the mineral composition of the alluvial clay-silt is consistent across the study area. Chemical analyses for the EPA 16 PAHs for sediment with depth are shown for Site A in Fig. 5. This borehole is 1 of 3 from the site which all show similar levels of contamination versus depth. These are bulk analyses (no distinction between matrix and pores) as the samples were homogenised.

The analyses confirmed the visual and olfactory observations in that substantial concentrations of contaminants are seen throughout the clay horizon clearly demonstrating that DNAPL contamination has traversed through the alluvial silt-clay to the sand-gravel aquifer $(13.2 \mathrm{~m})$. Total PAH concentrations ranged from $2.8 \mathrm{mg} / \mathrm{kg}$ (Borehole 1 , $9.8 \mathrm{~m}$ ) to $1200 \mathrm{mg} / \mathrm{kg}$ (Borehole $1,9.6 \mathrm{~m}$ ). Coal tar distillate (the pollutant at this site) comprising low to middle distillates is apparent in the PAH signature with the predominance of the lower molecular weight PAHs. The following trends are apparent in the PAH data; the total concentration within the soil drops sharply at the standing groundwater level observed in monitoring wells (c. $13 \mathrm{~m}$ b.g.l.). Above the groundwater capillary fringe, sediment was unsaturated (w.r.t water) and the coal tar distillate does not need to displace the water to occupy the soil pores. In addition, capillary pressures are lowest in the largest open
Fig. 5 Profile of the EPA 16 Polycyclic Aromatic Hydrocarbon concentrations versus depth for samples from Site A. Others = Sum of benzo(a)anthracene, chrysene, cyclopenta(cd)pyrene, benzo(b)fluoranthene, benzo(k)fluoranthene, benzo(e)pyrene, benzo(a)pyrene, dibenzo(ah)anthracene, benzo(ghi)perylene, indeno(123cd)pyrene, anthanthrene, acenaphthylene

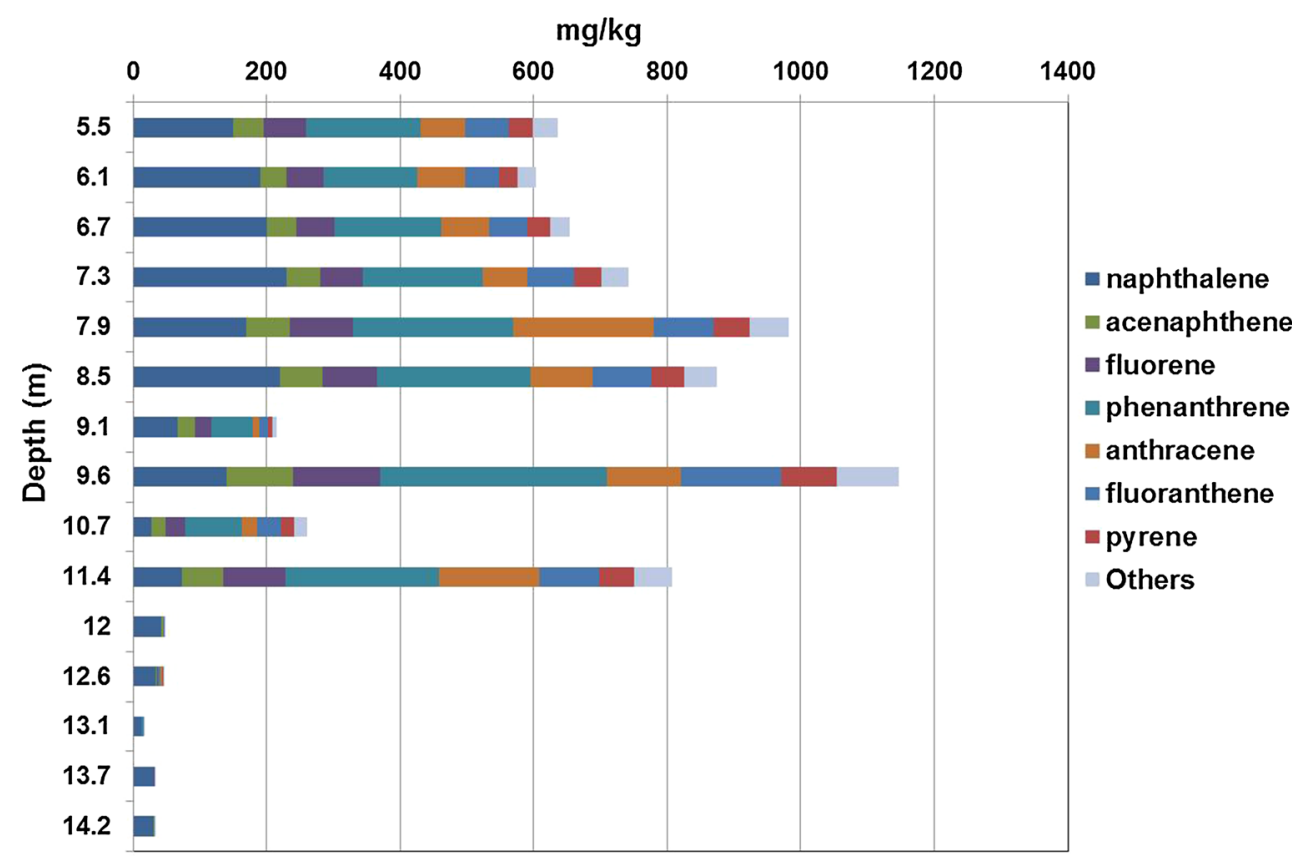


spaces, forcing the coal tar distillate to occupy these zones (at neutral $\mathrm{pH}$ water is preferentially wetting of silicate minerals in respect to coal tar distillate, thus coating the surface of minerals). The reduction in total soil PAH concentration below the groundwater level is thought to be attributable to the decrease in frequency of biopores (see below) rather than an inability of the coal tar distillate to displace water from pores. Due to the softness of sediment below the phreatic level, the network of biopores was often observed to be disrupted or absent because the soils moisture content exceeded the soils plastic limit.

Phenanthrene and naphthalene generally predominates in the cored material (cf. Vulava et al. 2007). The relative contribution of individual species appears to vary little although the relative proportion of naphthalene appears to vary most significantly. Variations may be due to loss by volatilisation during weathering which would lead to preferential loss of lower molecular weight PAH species, or partitioning to sediment organic matter, which would lead to preferential enrichment of high molecular weight PAH species. Below the groundwater level (c. $13 \mathrm{~m})$, naphthalene becomes the predominant PAH species recorded. Naphthalene is the most water soluble PAH present. However, solubility alone cannot explain the phenomena as free product (i.e. coal tar distillate at a concentration exceeding its solubility) were observed below the standing groundwater level and within the underlying sands and gravels at the site.

The high recorded concentrations confirm the presence of a free phase and contradict the expectations that the clay horizons are barriers to the movement of either dissolved or free-phase contaminants. It should be noted that since the analysis of total sediment concentrations was determined on homogenised pores and matrix sample, the actual pore concentration is diluted by matrix. The data in Fig. 5 are from a borehole which was close to a former buried coal tar distillate tank which account for the exceptionally high recorded concentrations.

Analyses of samples of separated matrix and pore sediment were carried out on materials from Site A and Site D. The total concentrations of naphthalene, fluorene, phenanthrene, anthracene, fluoranthene and pyrene in the biopores at Site D at depths of 3.00 and $4.00 \mathrm{~m}$ were 462 and $134 \mathrm{mg} / \mathrm{kg}$, respectively. The contaminants were not detected by analyses of the corresponding matrix material. Similarly for Site A, concentrations of the above PAHs at 6 and $8 \mathrm{~m}$ were 66 and $68 \mathrm{mg} / \mathrm{kg}$, respectively. At the $6 \mathrm{~m}$ depth, $15 \mathrm{mg} / \mathrm{kg}$ of these PAHs were detected in the matrix and they were not detected in the matrix at $8 \mathrm{~m}$ depth. These analyses support the visual and olfactory observations on core material from the study sites that demonstrate that contamination is transported via and remains concentrated in the biopores. This concurs with the findings of Jørgensen et al. (1998) but is notably different from the findings of Vulava et al. (2007).

\section{Biopores: characteristics and frequency of occurrence}

The alluvium contains abundant penetrations of open and fibre-filled pores with diameters of less than $2.5 \mathrm{~mm}$. The chemical, visual and olfactory evidence presented above demonstrates that the biopores transported DNAPL contaminants. A portion of the pores encountered in the alluvium contained fossil plant fragments (e.g. Figure 3d). The fragments were predominantly fibrous and roughly circular in cross section with diameters typically $<2.5 \mathrm{~mm}$, being predominantly orientated vertically to sub-vertically. Plant fragments observed within some pores were extremely delicate. Plant fibres supported by the soil matrix were observed to extend up to lengths exceeding the longest intact sections of retrieved core (i.e. $>450 \mathrm{~mm}$ ). The fossil plant fragments may reduce the permeability of the pore or serve as a 'wick' for hydrocarbon transport.

Biopore sizes typically ranged from 'pin-holes' too small to measure to pores of nearly $2.5 \mathrm{~mm}$ diameter, cf. Edwards et al. (1988) for comparison to the size distribution of worm biopores. The cross-sectional area of the logged samples varied, depending on the drilling technique used during site investigations. Biopore data from twenty-two samples taken from a range of depths at Site $\mathrm{A}$ and Site $\mathrm{C}$ are shown in Fig. 6. The cross-sectional area of the cores ranged from $7.9 \times 10^{-3}$ to $9.6 \times 10^{-6}$ $\mathrm{m}^{2}$. The cross-sectional area of the pores was calculated from their recorded diameter, assuming the pores were effectively circular. In the samples, studied biopores were found to account for between 5 and $230 \mathrm{~cm}^{2}$ per $\mathrm{m}^{2}$. This upper figure is $2.3 \%$ of the horizontal surface area of the alluvium and represents a pore volume of up to 23 litres per $\mathrm{m}^{3}$ of alluvium. Figure 7 demonstrates that there are no discernible trends with pore frequency (and hence projected area) of biopores with depth, showing that the biopores influence porosity throughout the depth of alluvium.

The matrix clay-silt alluvium is relatively impermeable $\left(k=10^{-10}-10^{-11} \mathrm{~m} / \mathrm{s}\right)$. Models have been developed for understanding flow through fractured heavily fractured clay horizons, using the hydraulic aperture approach (e.g. McKay et al. 1999; Hinsby et al. 1996 and references therein), although Jørgensen et al. (1998) found that this approach did not predict DNAPL movement in column experiments. Although high numbers of biopores were discovered per square metre (see Fig. 6), it is highly likely that assuming all pores are open and continuous will overestimate the permeability of the soil as a proportion of 
Fig. 6 Projected frequency (per $\mathrm{m}^{2}$ ) of occurrence of biopores of various diameter extrapolated from samples from Site A $(2 \times$ boreholes, $n=17)$ and Site $\mathrm{D}$ $(2 \times$ borehole, $n=5)$

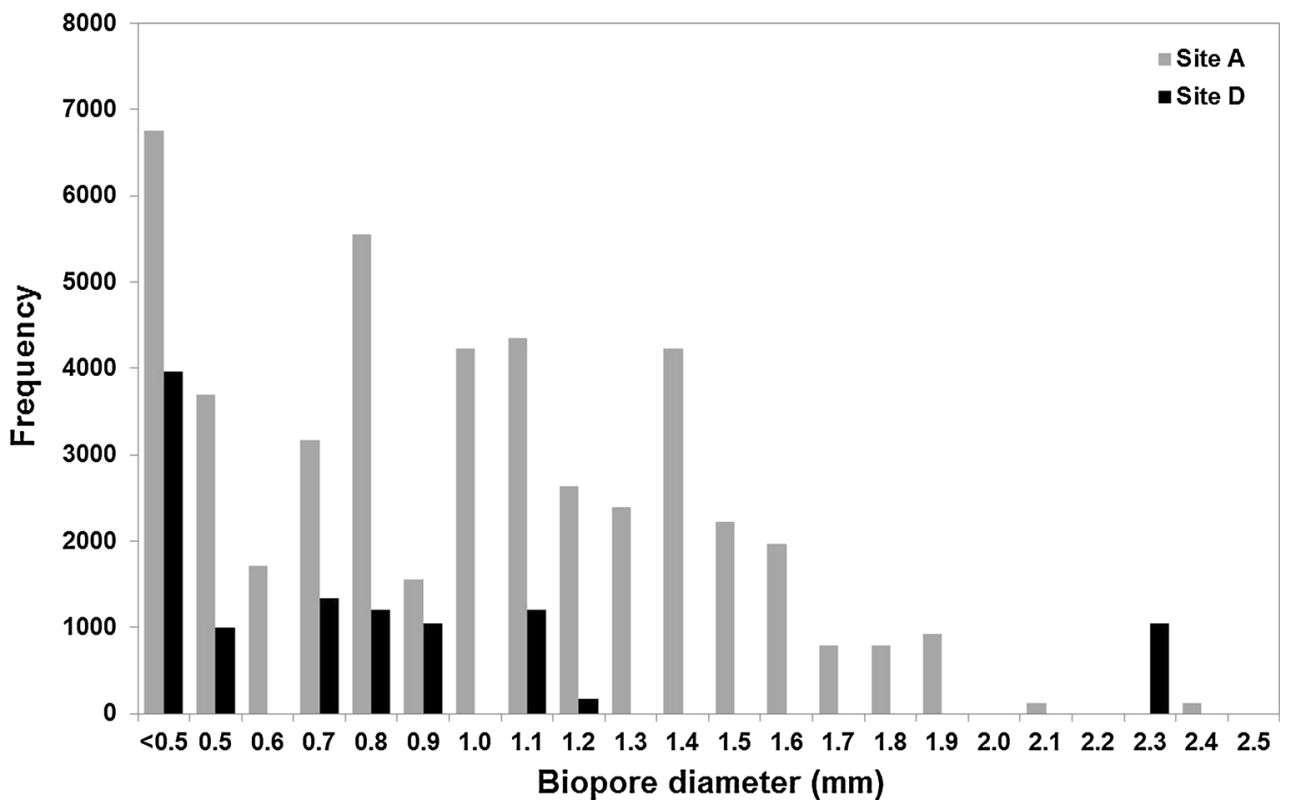

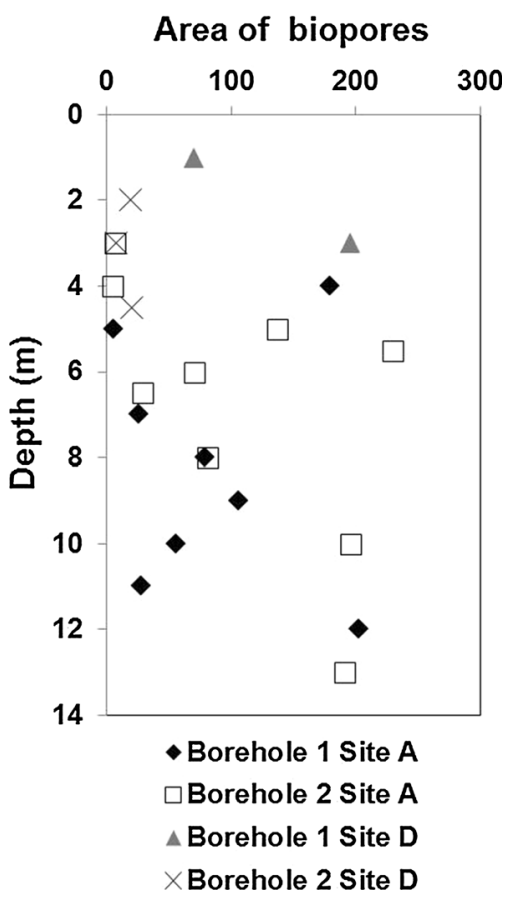

Fig. 7 Area (calculated from data in Fig. 6) of biopores $\left(\mathrm{cm}^{2}\right.$ per $\left.\mathrm{m}^{2}\right)$

biopores will be discontinuous and/or contain organic fragments. Biopores can also become infilled by soil fines (e.g. Figure 3c). Nevertheless, the fact that contamination has (as demonstrated by chemical analyses (Fig. 5) and observations of free-phase NAPL in the underlying groundwater) penetrated through the full depth of the alluvium is clear evidence that the biopores have increased the permeability of the alluvium with respect to NAPLs.

\section{Biopore capillary behaviour}

Wicking experiments with plant fragments isolated from core samples demonstrated that plant fibres which comprise a network of microscopic pores results in rapid and significant capillary rise. The length of plant fibre obtained was limited due to the extremely delicate nature of the fibres. In all ten experiments on isolated plant fragments, coal tar distillate was observed to rise rapidly through the entire length of the fibres which extended up to $30 \mathrm{~mm}$ above the coal tar distillate. The tests performed on plant fibres in confinement of soil matrix resulted in coal tar distillate rising up to $120 \mathrm{~mm}$ within the fibres after $24 \mathrm{~h}$ of contact with coal tar distillate. It was apparent in later dissection of tests samples comprising multiple plant fibres that coal tar distillate did not appear on some fibres suggesting that some vertical/sub-vertical fibres were discontinuous.

The results of the capillary rise experiments performed in artificially formed open pores in alluvium are presented in Fig. 8. These experiments demonstrate that in an air/ NAPL/silicate mineral system, coal tar distillate is preferentially wetting. The degree of capillary rise within artificial pores in alluvium compares favourably with those observed in glass capillaries. Cohen et al. (2007) reported a sessile contact angle between coal tar distillate and glass in a coal tar distillate/glass/air system of $170^{\circ}$ (i.e. a glass/coal tar distillate contact angle of $10^{\circ}$ ). Substituting this angle into Eq. (1) along with the capillary rise data above allows the calculation of the liquid-air surface tension, $\gamma$.

$\gamma=h \rho g r / 2 \cos \theta$ 


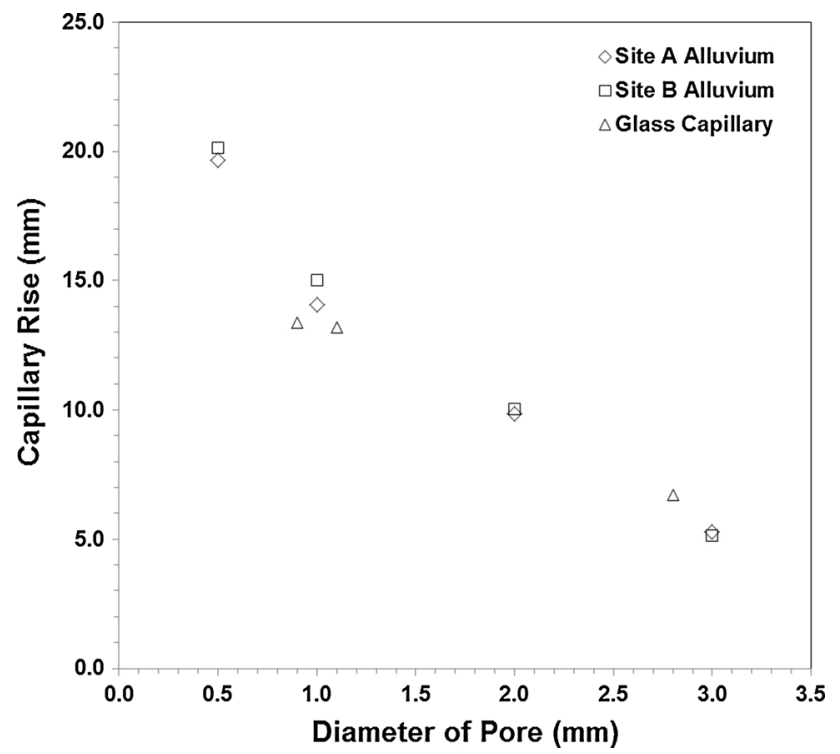

Fig. 8 Average $(n=3)$ capillary rise versus pore diameter after $1 \mathrm{~h}$ of contact for open pores in alluvium and within glass capillary tubing

where $\gamma$ liquid-air surface tension; $\rho$ density; $r$ pore radius; $g$ acceleration due to gravity; and $\theta$ contact angle

Parameters used to $(\gamma)$ include a density of coal tar distillate $(\rho)$ of $1085 \mathrm{~kg} / \mathrm{m}^{3}$ (the mid-point of range quoted by Rutgers 2003); acceleration due to gravity $(g)$ of $9.81 \mathrm{~ms}^{-2}$; a contact angle $(\theta)$ of $10^{\circ}$ (from Cohen et al. 2007). Using the average capillary rise data and the coal tar distillate/glass contact angle calculated from Cohen et al. (2007), the liquid-air surface tension was $( \pm \mathrm{stdv}) 8.06 \times$ $10^{-2}\left( \pm 1.93 \times 10^{-2}\right) \mathrm{J} / \mathrm{m}^{2}$ for Site A; $8.16 \times 10^{-2}$ $\left( \pm 1.90 \times 10^{-2}\right) \mathrm{J} / \mathrm{m}^{2}$ for Site B. This compares to a value of $8.17 \times 10^{-2}\left( \pm 1.50 \times 10^{-2}\right) \mathrm{J} / \mathrm{m}^{2}$ for tests done with glass capillaries. These values can be used in the calculation of capillary forces above the phreatic level in siliceous clay in liquid-air surface tension. During these experiments, samples were at their natural moisture content and capillary rise into the soil matrix (i.e. the soil matrix beyond the biopore structures) was not observed over the duration of the experiments.

A capillary-related effect was also noted during field observations (Site C) for the subordinate peat bands observed within the alluvium: coal tar-free product had migrated several tens of metres horizontally from its source (a former gasworks) along a thin layer peat horizon. Whilst the organic matter in peat has a propensity to sorb PAH from solution thereby retarding its movement in aqueous phase, its open fibrous structure is likely to contribute to the transport DNAPL free product via capillary forces.

\section{Conclusions}

The Severn Estuary clay-silt alluvium was found to contain fossil rootlet biopores of vertical to sub-vertical in orientation. Many of the biopores contained plant fragments showing them to be rootlet biopores. Field observations have revealed that at industrial sites where coal tar/coal tar distillate has escaped to the subsurface that the DNAPL contamination has migrated up to $13 \mathrm{~m}$ through the clay-silt to contaminate the underlying gravel aquifer due to the presence of the biopores which act as contaminant conduits.

The areas of biopores projected from samples were $5-230 \mathrm{~cm}^{2}$ per $\mathrm{m}^{2}$. This upper figure represents a pore volume of up to 23 litres per $\mathrm{m}^{3}$ of alluvium $(2.3 \%)$. There were no discernible trends with pore frequency (and area) of biopores with depth above the phreatic surface and the biopores influence porosity throughout the depth of alluvium. The fossil biopores are easily disturbed, which reduce the apparent permeability of soils upon testing. Biopore frequency decreases dramatically below depth of groundwater, as did recorded concentrations of PAH contaminants. This is not due to the inability of DNAPL to displace water from the pores as contaminated pores were observed beneath the phreatic level, rather than when the sediment is saturated, the plastic limit is exceeded and the soil no longer preserved the biopores. The majority of the alluvial sediment has a moisture content approaching or exceeding the soils plastic limit, and clay-silt sediments were typically soft to very soft. Smearing and destruction of biopores by cutting core and preparing for analyses are a problem and compromises hydraulic conductivity determinations.

DNAPL contamination was seen to lie predominantly within the biopores with the soil matrix holding little contamination. In addition to the gravity-driven flow usually considered in groundwater/contaminant transport equations, it has been qualitatively shown that above the phreatic surface, capillary forces can play a significant part in the migration of coal tar distillate through alluvial clay via a network of open and fibre-filled pores. The fossil plant fibres encountered in some biopores appear especially effective at wicking coal tar distillate due to their internal network of microscopic pores essential to the function of the plant.

Fossil rootlet biopores were shown to exist throughout the entire depth of the alluvium, presumably due to deposition under transgression, demonstrating the importance of understanding the paleoenvironment and depositional geology in evaluating groundwater risk. 


\section{Compliance with ethical standards}

Conflict of interest The authors declare that they have no conflict of interest.

Open Access This article is distributed under the terms of the Creative Commons Attribution 4.0 International License (http://crea tivecommons.org/licenses/by/4.0/), which permits unrestricted use, distribution, and reproduction in any medium, provided you give appropriate credit to the original author(s) and the source, provide a link to the Creative Commons license, and indicate if changes were made.

\section{References}

Allen JRL, Fulford MG (1986) The wentlooge level: a RomanoBritish saltmarsh reclamation in southeast wales. Britannia 17:91-117

British Geological Survey (1975) Sheet 249 Newport, 1:50,000 Series Geological Survey of England and Wales

British Geological Survey (1980) Sheet 279 Weston-super-Mare, 1:50,000 Series Geological Survey of England and Wales

British Geological Survey (1986a) Sheet 264 Portishead, 1:50,000 Series Geological Survey of England and Wales

British Geological Survey (1986b) Sheet 263 Cardiff, 1:50,000 Series Geological Survey of England and Wales

British Standards Institute: BS 1377 (1990) Methods of test for soil for civil engineering purposes. Part 6: Consolidation and permeability tests in hydraulic cells and with pore pressure measurement. British Standards Institute. ISBN 0580185885

British Standards Institute: BS 5930 (1999). Code of Practice for site investigation. British Standard Institute. ISBN 0580330591

BS 10175 (2001) Investigation of Potentially Contaminated Sites: Code of Practice. ISBN 9780580681981

Cohen RM, Mercer JW, Slenska M, Brourman M (2007) Creosote wettability review and evaluation at a portion of the Cabot Carbon/Koppers Superfund site. In: The proceedings of the 2nd international conference on DNAPL characterisation and Remediation, Niagara Falls, September 24-27, 2007

Douglas JT (1986) Macroporosity and permeability of some soil cores from England and France. Geoderma 37(3):221-231

Driese SG, McKay L, Penfield C (2001) Lithogenic and pedogenic influences on porosity distribution and groundwater flow in fractured sedimentary saprolite: A new application of environmental sedimentology. J Sediment Res 71:843-857

Edwards WM, Shipitalo MJ, Norton LD (1988) Contribution of macroporosity to infiltration into a continuous corn no-tilled watershed: implications for contaminant movement. J Contam Hydrol 3(2):193-205
Hatheway AW (2002) Geoenvironmental protocol for site and waste characterization of former manufactured gas plants; worldwide remediation challenge in semi-volatile organic wastes. Eng Geol 64(4):317-338

Hinsby K, McKay LD, Jørgensen P, Lenczewski M, Gerba CP (1996) Fracture aperture measurements and migration of solutes, viruses, and immiscible creosote in a column of clay-rich till. Groundwater 34(6):1065-1075

Jones RL, Keen DH (1993) Pleistocene environments in the British Isles. Springer, Netherlands

Jørgensen PR, Broholm K, Sonnenborg TO, Arvin E (1998) DNAPL transport through macroporous, clayey till columns. Groundwater 36(4):651-660

Kellaway GA, Welch FBA (1993) Geology of the Bristol district. Memoir of the British Geological Survey. HMSO, London

McKay LD, Fredericia J (1995) Distribution, origin, and hydraulic influence of fractures in a clay-rich glacial deposit. Can Geotech J 32(6):957-975

McKay LD, Fredericia J, Lenczewski M, Morthorst J, Klint KES (1999) Spacial variability of contaminant transport in a fractured till, Avedore Denmark. Nordic Hydrol 30:333-360

McKay LD, Driese SG, Smith KH, Vepraskas MJ (2005) Hydrogeology and pedology of saprolite formed from sedimentary rock, eastern Tennessee, USA. Geoderma 126:27-45

Mueller JG, Chapman PJ, Pritchard PH (1989) Creosote-contaminated sites. Environ Sci Technol 23:1197-1201

Oades JM (1993) The role of biology in the formation, stabilization and degradation of soil structure. Geoderma 56(1):377-400

Rodvang SJ, Simpkins WW (2001) Agricultural contaminants in Quaternary aquitards: a review of occurrence and fate in North America. Hydrogeol J 9:44-59

Rudolf DL, Cherry JA, Farvolden RN (1991) Groundwater flow and solute transport in fractured lacustrine clay near Mexico City. Water Resour Res 27:2187-2201

Rutgers Chemicals (2003) Creosote. Preservative for industrial wood impregnation. Technical Information Sheet

Shaw RJ, Hendry MJ (1998) Hydrogeology of a thick clay till and Cretaceous clay sequence, Saskatchewan, Canada. Can Geotech J 35:1041-1052

Squirrell HC, Downing RA (1969) Geology of the South Wales Coalfield, Part 1: the country around Newport. Her Majesty's Stationery Office

Vulava VM, McKay LD, Driese SG, Menn FM, Sayler GS (2007) Distribution and transport of coal tar-derived PAHs in finegrained residuum. Chemosphere 68(3):554-563

White RA, Rivett MO, Tellam JH (2008) Paleo-roothole facilitated transport of aromatic hydrocarbons through a Holocene clay bed. Environ Sci Technol 42(19):7118-7124 